First publ. in: Journal of Molecular Evolution 48 (1999), 6, pp. 703-711

\title{
Mitochondrial DNA Phylogeny of the Family Cichlidae: Monophyly and Fast Molecular Evolution of the Neotropical Assemblage
}

\author{
Izeni P. Farias, ${ }^{1,2}$ Guillermo Ortí, ${ }^{2}$ Iracilda Sampaio, ${ }^{3}$ Horacio Schneider, ${ }^{3}$ Axel Meyer ${ }^{4}$ \\ ${ }^{1}$ Departamento de Biologia, Instituto de Ciências Biológicas, Universidade do Amazonas, 69077-000, Estrada do Contorno 3000, Manaus, \\ Amazonas, Brasil \\ ${ }^{2}$ School of Biological Sciences, 314 Manter Hall University of Nebraska, Lincoln, NE 68588-0118, USA \\ ${ }^{3}$ Departamento de Genética, Centro de Ciências Biológicas, Universidade Federal do Pará, Belém, Pará, Brasil \\ ${ }^{4}$ Department of Biology, P.O. Box M617, University of Konstanz, D-78457 Konstanz, Germany
}

Received: 18 September 1998 / Accepted: 16 December 1998

\begin{abstract}
A mitochondrial DNA (mtDNA) phylogeny of cichlid fish is presented for the most taxonomically inclusive data set compiled to date (64 taxa). 16S rDNA data establish with confidence relationships among major lineages of cichlids, with a general pattern congruent with previous morphological studies and less inclusive molecular phylogenies based on nuclear genes. Cichlids from Madagascar and India are the most basal groups of the family Cichlidae and sister to African-Neotropical cichlids. The cichlid phylogeny suggests drift-vicariance events, consistent with the fragmentation of Gondwana, to explain current biogeographic distributions. Important phylogenetic findings include the placement of the controversial genus Heterochromis basal among African cichlids, the South American genus Retroculus as the most basal taxon of the Neotropical cichlid assemblage, and the close relationship of the Neotropical genera Cichla with Astronotus rather than with the crenicichlines. Based on a large number of South American genera, the Neotropical cichlids are defined as a monophyletic assemblage and shown to harbor significantly higher levels of genetic variation than their African counterparts. Relative rate tests suggest that Neotropical cichlids have experienced accelerated rates of molecular evolution. But these high evolutionary rates were significantly higher among geophagine cichlids.
\end{abstract}

Correspondence to: Axel Meyer; e-mail: axel.meyer@uni-konstanz.de
Key words: Cichlid fish - Phylogeny - Mitochondrial DNA - Heterochromis - Systematics - DNA substitution rate

\section{Introduction}

Freshwater fish of the family Cichlidae live throughout Africa, the Neotropics, Madagascar, and India. This distribution implies an ancestral Gondwana-wide range dating back at least 130 million years (Ma) and an age of origin ostensibly old in light of the currently available fossil evidence (Lundberg 1993). Monophyly of the family Cichlidae and phylogenetic relationships among the main cichlid lineages were assessed using morphological characters (e.g., Kaufman and Liem 1982; Stiassny 1987; Stiassny 1991) and nuclear DNA markers (Zardoya et al. 1996; Streelman and Karl 1997; Streelman et al. 1998) (Fig. 1). The phylogeny of cichlids supports a simple vicariance hypothesis to account for their distribution. In agreement with the pattern of fragmentation of the Gondwana supercontinent (Storey et al. 1995), molecular and morphological studies place the Madagascar and Indian taxa as the most basal groups in the cichlid phylogeny, followed by the African and Neotropical taxa, forming putative monophyletic sister groups (Fig. 1). The phylogenetic position of the Congo genus Heterochromis remains unresolved and disputed and had, before this study, been studied only through morphological data (Ol- 


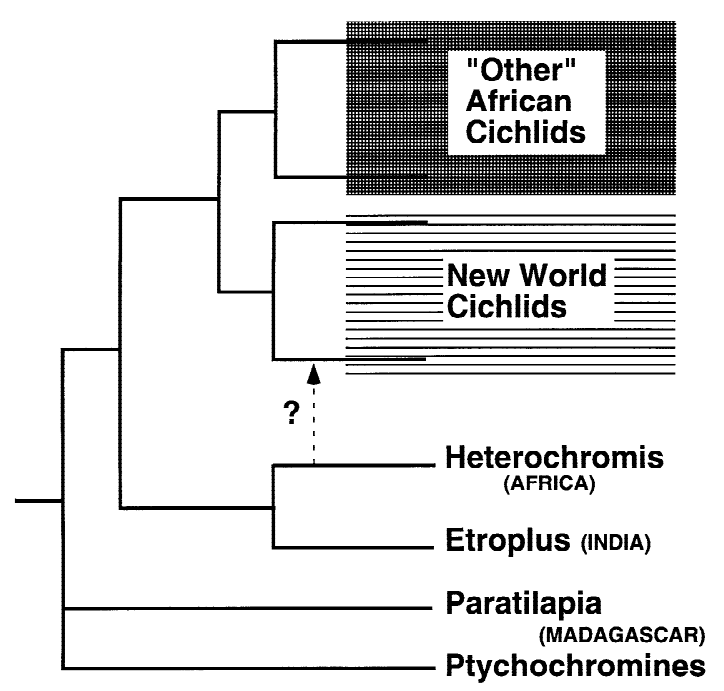

Fig. 1. Phylogenetic relationships of the major groups of cichlid fish based on morphological characters according to Stiassny (1991) and supported (in part) by nuclear molecular markers, except for the controversial position of the African genus Heterochromis. While Stiassny (1991) suggested a close relationship of Heterochromis with etroplines, Kullander (1998) placed it among basal Neotropical cichlids.

iver 1984; Stiassny 1991; Kullander 1998)—molecular data for it have been missing.

Most molecular phylogenetic investigations to date (e.g., Meyer et al. 1990; Sturmbauer and Meyer, 1992; Moran and Kornfiled 1993; Kocher et al. 1995) have focused on the relationships among East African lacustrine cichlids, which comprise more than $70 \%$ of the species in the family (Kullander 1998) and constitute a textbook example of adaptive radiations, rapid speciation, and trophic specialization (Futuyma 1997). These studies have shown a remarkably low level of genetic divergence in the face of a very rapid rate of intralacustrine speciation (Meyer et al. 1990). Conversely, the mainly riverine Neotropical cichlids, with less than 30\% of the species in the family, seem to exhibit larger genetic divergences. Genetic variation at a nuclear locus among African cichlids was about half that reported for a few Neotropical taxa, suggesting that African cichlids may have a slower rate of molecular evolution (Zardoya et al. 1996). The Neotropical riverine fauna is morphologically diverse and geographically widespread and seems to have conserved ancestral morphological patterns (Kullander 1998) but has been relatively poorly studied with molecular data (Roe et al. 1997; Farias et al. 1998; Martin and Bermingham 1998). Additional comparisons of the patterns of phylogenetic divergence (morphological and molecular) and speciation within the major cichlid clades should further our understanding of cichlid evolution and the recent radiation of the East African lineages.

The evolutionary histories of African and New World cichlids seem to differ in fundamental ways. The first review of the entire Neotropical cichlid fauna was published more than 90 years ago by Regan (1906). He separated the genus Cichla from the rest of the Neotropical assemblage (approximately 40 genera) and identified Chaetobranchus as the basal lineage in the radiation of Neotropical cichlids. Since then, the phylogenetic position of Cichla has remained controversial and enigmatic (Cichoki 1976; Oliver 1984; Kullander 1986, 1988; Stiassny 1987, 1991) but is of particular importance for the resolution of intrafamilial relationships. Kullander (1998) recently proposed a new phylogeny and classification of the Cichlidae, focusing on the South American assemblage. He placed Retroculus as the most basal genus of an otherwise paraphyletic Neotropical cichlid clade that includes Cichla as well as the African genus Heterochromis. Molecular studies have so far included only a few Neotropical genera. Zardoya et al. (1996) included only four (Astronotus, Cichla, Cichlasoma, and Crenicichla), and Sültmann et al. (1995) only three (Cichla, Cichlasoma, and Thorichthys). These few genera were used as representatives of a putatively monophyletic Neotropical clade for the assessment of phylogenetic relationships among the major cichlid lineages. More extensive taxonomic sampling of Neotropical cichlids has been carried out by Roe et al. (1997) and Martin and Bermingham (1998) on Central American heroines and by Farias et al. (1998) on South American cichlasomines and heroines. In our previous study (Farias et al. 1998), we reported phylogenetic relationships among 24 cichlid taxa, including 19 from South America, 1 from Central America, and 4 from Africa, based on $550 \mathrm{bp}$ of the mitochondrial $16 \mathrm{~S}$ rRNA gene. In an attempt to obtain a broader picture of the evolutionary relationships among South American cichlid genera, we present an expanded data set including 47 Neotropical species. Together with representatives of all major African lineages (17 species included) and Madagascar cichlids, the present report is the most complete molecular phylogenetic sample of cichlid taxa to date. Increasing the sampling density in poorly represented clades by the addition of new taxa also intends to break up "long branches" and improve the accuracy of phylogenetic inference (Felsenstein 1978; Hillis 1998).

\section{Materials and Methods}

\section{Samples and DNA Methods}

Sixty-four taxa representing the major groups from the family Cichlidae were included in the present study. Voucher specimens for most South American samples were deposited in museum collections (Appendix). Definition of suprageneric groups within the cichlids (e.g., cichlasomines, crenicichlines, geophagines, etc.; see Figs. 2 and 3) follows common usage and does not have formal systematic implications (Stiassny 1991). A complete list of suprageneric Neotropical groups is provided by Kullander (http://www.nrm.se/ve/pisces/acara/ cichtabl.html.en). The pomacentrid Abudefduf sp. and the embiotocid Cymatogaster aggregata were used as outgroup.

Total DNA was isolated by standard proteinase K, phenol/ 


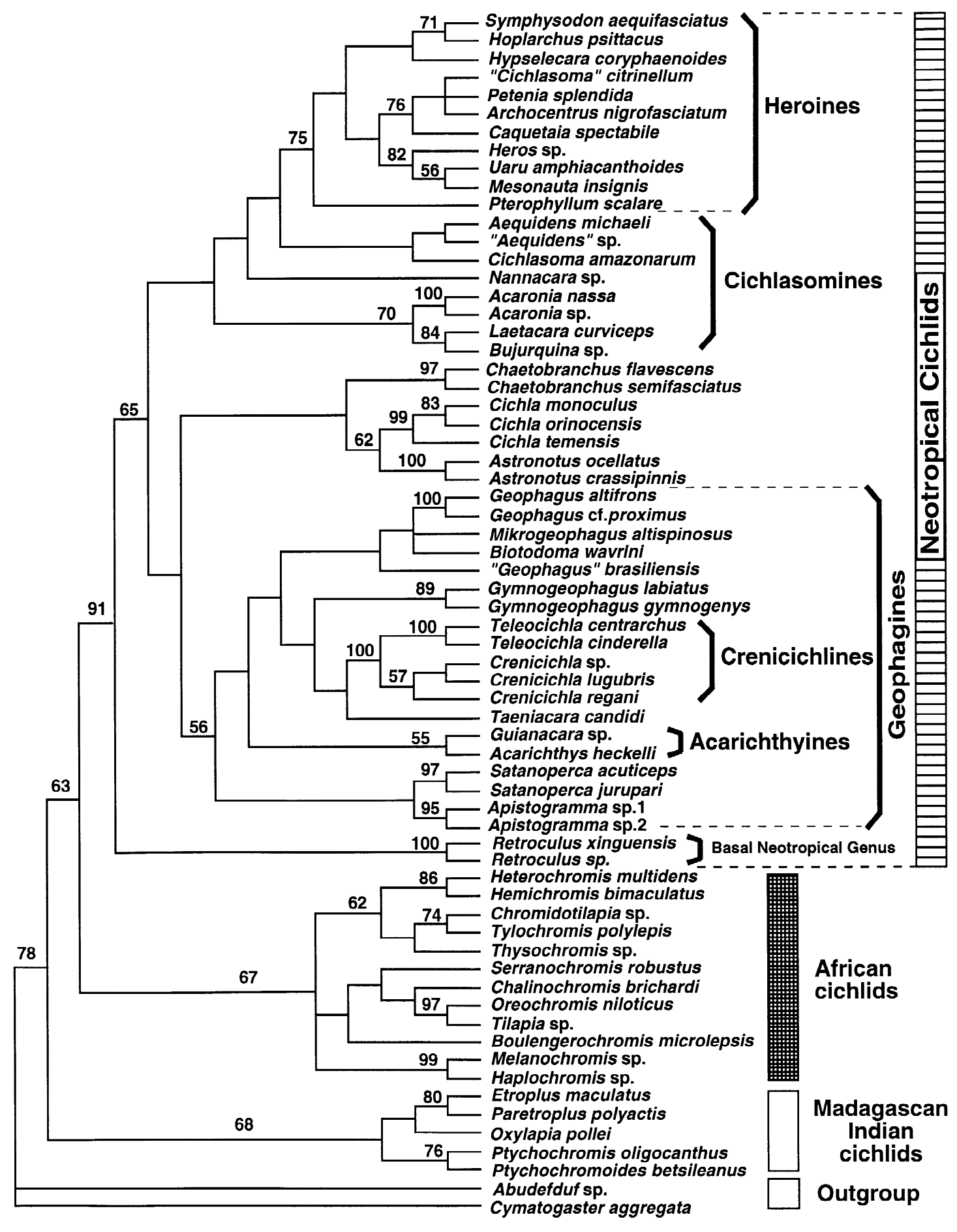

Fig. 2. Strict consensus of eight MP trees. Numbers above branches are bootstrap values (only values above 50 are shown).

chloroform extraction (Sambrook et al. 1989). PCR was carried out in 100- $\mu \mathrm{l}$ reaction tubes containing $59 \mu \mathrm{l} \mathrm{H}_{2} \mathrm{O}, 16 \mu \mathrm{l}(5 \mathrm{mM}) \mathrm{dNTP}, 10$ $\mu \mathrm{l}(10 \times)$ reaction buffer, $8 \mu \mathrm{l}(25 \mathrm{mM}) \mathrm{MgCl}_{2}, 1 \mu \mathrm{l}(200 \mathrm{ng})$ each primer, $5 \mu \mathrm{l}$ DNA (200 ng/ $\mu \mathrm{l}$ ), and $2.5 \mathrm{U}$ Taq DNA polymerase. PCR was performed using 25 cycles at $93^{\circ} \mathrm{C}$ for $1 \mathrm{~min}, 50^{\circ} \mathrm{C}$ for $1 \mathrm{~min}$, and $72^{\circ} \mathrm{C}$ for 2 min. Conserved primers $16 \mathrm{Sa}-\mathrm{L} 2510$ and $16 \mathrm{Sb}-\mathrm{H} 3080$ (Palumbi et al. 1991) were used for PCR and sequencing. Some samples were sequenced manually using the Thermo Sequenase cycle sequencing kit (Amersham Life Science) and $\alpha-{ }^{35}$ S-labeled dATP. Other samples were sequenced using the BigDye Terminator cycle sequencing ready reaction kit (Applied Biosystems Inc.) on an auto- mated DNA sequencer (Applied Biosystems 310) following the manufacturer's instructions. All templates were sequenced completely in both directions. The nucleotide sequence data determined for the present paper were deposited in GenBank (accession numbers: AF045842AF045865, AF048996-AF049019, AF112577-AF112596).

\section{Sequence Alignment and Phylogenetic Analyses}

DNA sequences were aligned using CLUSTALW 1.5 (Thompson et al. 1994). Settings for CLUSTALW were opening gap cost $=20$ and 


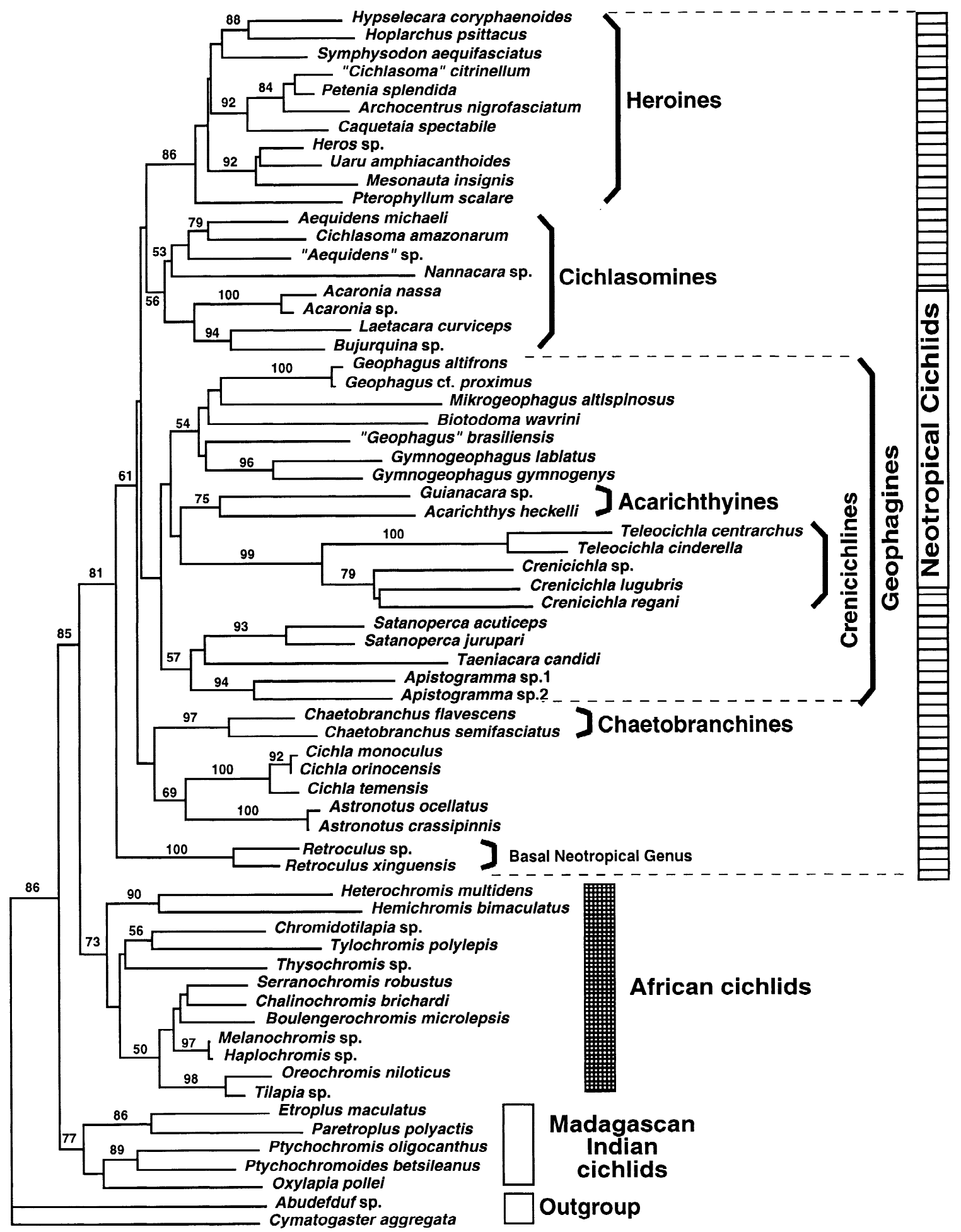

Fig. 3. ME tree obtained using HKY $+\Gamma$ distances $(\mathrm{ME}$ score $=3.75, T$ ratio $=2.45$, Pinvar $=0.39, \Gamma$ shape $=0.67)$. Numbers above branches are bootstrap values (only values above 50 are shown). Highlighted branches identify the highest rates of evolution as suggested by relative rates tests; see text and Fig. 4.

extending gap cost $=5$. The final alignment comprised 564 positions. Phylogenetic analyses were conducted using PAUP* version 4.0d64 (Swofford 1998). A heuristic search with 50 repetitions using random stepwise additions was performed under maximum parsimony (MP). Nonparametric bootstrapping was based on 100 replicates (each with
10 random addition steps). Gaps were treated as “missing." Minimumevolution (ME) methods (Kidd and Sgaramella-Zonta 1971) were also applied to the data, using maximum-likelihood distances based on the HKY $+\Gamma$ model (Hasegawa et al. 1985; Yang 1993). This model takes into account the transitional bias and among-site rate heterogeneity 
observed for the 16S fragment (Ortí and Meyer 1997). Parameters for this model (transition/transversion rate, proportion of invariable sites, and $\Gamma$ shape parameter) were estimated by optimizing the data on the MP trees. Comparisons of mean distance measures for each major clade were also based on this model.

Constancy of nucleotide substitution rates among Neotropical and African cichlids was tested using relative rate tests based on the twocluster test of Takezaki et al. (1995), as implemented in the PHYLTEST program (Kumar, 1996). This test examines the equality of the average substitution rate for two monophyletic lineages-in this case, African and Neotropical cichlids, using the Madagascar-Indian cichlids as outgroup

Alternative phylogenetic hypotheses (e.g., Kullander 1998, Stiassny 1991) were tested against the most-parsimonious trees obtained with our data using maximum-likelihood ratio tests (Kishino and Hasegawa 1989) and Wilcoxon signed-rank tests (Templeton 1983), as implemented in PAUP* version 4.0d64. Most-parsimonious trees satisfying topological constraints imposed by the alternative hypotheses were obtained for the $16 \mathrm{~S}$ data set. These trees were then compared to the most-parsimonious "unconstrained" trees.

\section{Results}

\section{Patterns of Nucleotide Divergence}

Of a total of $564 \mathrm{bp}$ considered for the analysis, 274 characters were variable and 205 were phylogenetically informative under parsimony. The mean base composition was $29 \% \mathrm{~A}, 22 \% \mathrm{~T}, 26 \% \mathrm{C}$, and $23 \% \mathrm{G}$, confirming a slight over representation of $\mathrm{A}$ and $\mathrm{C}$, as observed in the mitochondrial 16S fragment of other fish (Ortí et al. 1996). The estimated transition/transversion rate was 2.48. A bias in favor of transitions over transversions has been found in all genes of the mitochondrial genome examined so far (reviewed by Meyer 1994). The other parameters estimated for the HKY $+\Gamma$ model were proportion of invariable sites $=0.34$ and $\Gamma$ shape $=0.52$. The maximum pairwise divergence value observed among all taxa was 0.20 (uncorrected " $p$ " distance) between Paretroplus polyactis and Teleocichla centrarchus. Most other pairwise comparisons had divergence values $p<0.17$. Based on several comparisons of fish taxa at different taxonomic levels, Ortí and Meyer (1997, p. 93) determined that the $16 \mathrm{~S}$ fragment reaches a saturation level at approximately $p=0.22$. Therefore, divergence values among cichlid species found in the present study appear to be below the saturation level for this molecule. All positions and substitution types were thus assigned the same weight in the phylogenetic analyses.

\section{Phylogenetic Analyses}

Parsimony analyses resulted in $12 \mathrm{MP}$ trees (length = 1493 , consistency index $=0.31$, retention index $=0.56$ ) a strict consensus of which is shown in Fig. 2. Differences among the MP trees involve relationships among the Central American cichlids "Cichlasoma," Archocen- trus, and Petenia and among the geophagines Mikrogeophagus, Biotodoma, and Geophagus. Minimum evolution resulted in a single tree (score $=2.49$; Fig. 3). There is overwhelming agreement between the MP and the ME results and previous hypotheses based on morphology and nuclear markers (Fig. 1). All of the above support the monophyly of the Cichlidae, the basal position of the Madagascar/Indian cichlids, and the monophyly of the African and Neotropical cichlids but disagree on the placement of the controversial genus Heterochromis.

In our analyses, the African genus Heterochromis often grouped with Hemichromis, in both MP and ME trees, defining a monophyletic African clade. Maximumlikelihood ratio tests and Wilcoxon signed-rank tests were applied to test alternative hypotheses regarding the position of Heterochromis. According to Stiassny (1991, Fig. 1.3), Heterochromis forms a group with etroplines but Kullander (1998) placed Heterochromis among the basal Neotropical genera (Fig. 1). Both of these hypotheses were optimized for the $16 \mathrm{~S}$ data using MP heuristic searches under topological constraints. Constrained searches resulted in 108 equally parsimonious trees satisfying Kullander's hypothesis (length $=1510$ ) and 1792 equally parsimonious trees (length $=1514$ ) satisfyinng Stiassny's hypothesis. Differences between the best MP tree (Fig. 2; length = 1493) and trees satisfying the alternative hypotheses were not always statistically significant. Templeton tests rejected 81.5 and $95.3 \%$ of the trees satisfying Kullander's and Stiassny's hypotheses, respectively. These results suggest the inclusion of Heterochromis, probably basal within a monophyletic African clade. However, maximum-likelihood tests did not show significant differences among trees.

The Neotropical cichlids have been divided into the following suprageneric groups, without the implication of a formal classification: heroines, cichlasomines, geophagines, crenicichlines, and chaetobranchines (Kullander 1983, 1986). Representatives of all these groups were included in the present study, and the above classification is corroborated in part by our molecular data. One of the differences between the ME and the MP trees obtained in the present study concerns the monophyly of cichlasomines. While ME supports a cichlasomine clade (bootstrap value $=56 \%$; Fig. 3), MP does not (Fig. 2). Of the seven cichlasomine genera included, Acaronia, Laetacara, and Bujurquina consistently grouped together in both types of analyses, whereas the placement of Nannacara, Cichlasoma, and Aequidens varied. The monophyly of heroines was well supported by the $16 \mathrm{~S}$ data and three major clades were found: (1) Symphysodon (Hoplarchus + Hypselecara); (2) Uaru, Heros, and Mesonauta; and (3) "Cichlasoma," Petenia, Archocentrus, and Caquetaia. The relationship of taxa within and among these clades, however, was not well defined. 
Pterophyllum was identified in the ME and MP trees as the basal genus of the heroine group (Figs. 2 and 3).

Despite low bootstrap values, geophagine monophyly (including the crenicichlines) was supported in all analyses (Figs. 2 and 3). Twelve genera (19 species) were included in the present study. ME and MP trees presented differential internal arrangements for the geophagines (Figs. 2 and 3). Bootstrap values of more than $50 \%$ were observed only for clades formed by the crenicichlines (Teleocichla + Crenicichla) and acarichthyines (Acarichthys + Guianacara) in the ME and MP trees, respectively. The relationship among Geophagus, Mikrogeophagus, Biotodoma, “G.” brasiliensis, Satanoperca, Apistogramma, and Taenicara varied in the different analyses.

Our analyses placed the genus Retroculus as the most basal group in the Neotropical radiation and clearly suggested that Cichla is included in the Neotropical clade. The Cichla + Astronotus arrangement was found in both $\mathrm{ME}$ and MP trees, as was found before for a limited set of Neotropical cichlids by nuclear DNA studies (Zardoya et al. 1996). But different arrangements were observed among the major Neotropical lineages (Figs. 2 and 3).

A Cichla-crenicichline clade has been proposed by Stiassny (1991) and more recently by Kullander (1998). However, the position of Crenicichla among Neotropical cichlids remains uncertain (Stiassny 1991, Fig. 1.5), but it clearly does not form a clade with Cichla based on DNA data. To test the relationships of Cichla and crenicichlines, we applied statistical comparisons using maximum-likelihood ratio and Wilcoxon signed-rank tests. For this analysis we used a simplified data set with only Neotropical taxa and four African genera as outgroup. Unconstrained parsimony analysis resulted in 14 MP trees (length =967), similar in topology to Fig. 2 (grouping crenicichlines, but not Cichla, within geophagines). Constrained searches under Stiassny's hypothesis resulted in $16 \mathrm{MP}$ trees (length > 985) grouping Cichla with crenicichlines outside of geophagines. Templeton tests rejected $88 \%$ of trees supporting Stiassny's hypothesis. These results support the grouping of crenicichlines within geophagines, with the exclusion of Cichla. However, maximum-likelihood tests did not show significant differences among trees.

\section{Rates of Molecular Evolution}

Because African and Neotropical cichlids are monophyletic sister groups, they are, by definition, of the same absolute age, following their divergence from a most recent common ancestor (MRCA). Path lengths across the ME tree (Fig. 3), from the MRCA to each representative African and Neotropical genus are plotted in Fig. 4. Differences in genetic distances from the MRCA to the tip of each branch represent rate variation among
$16 S$ rDNA

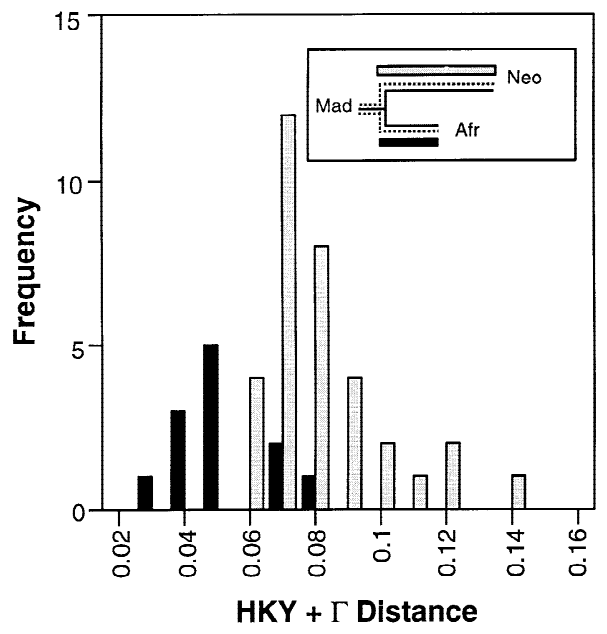

Fig. 4. Frequency distribution of genetic distances among cichlids $(\mathrm{HKY}+\Gamma$ distances). Path lengths across the ME tree from the most common recent ancestor (MRCA; see insert) to Neotropical genera (Neo; hatched bars) and African genera (Afr; solid bars). Mad, Madagascan/Indian cichlids. To minimize the effect of nonindependence among distances, a single representative of each Neotropical genus was used when more than one species per genus was available. A slower rate is inferred for African cichlids based on the shorter path length from Madagascar/Indian to African cichlids than to Neotropical cichlids.

lineages. Higher rates of evolution in Neotropical lineages are suggested by the distribution of these genetic distances. This result also was confirmed by relative rate tests (Takezaki et al. 1995). The $Z$ statistic $(Z=2.5609)$ rejected rate constancy $(p<0.05)$ among African and Neotropical lineages, showing that the average distance between the MRCA and the Neotropical cichlids ( $\mathrm{La}=$ 0.0967) and between African cichlids $(\mathrm{Lb}=0.0617)$ was significantly different $(\mathrm{La}-\mathrm{Lb}=0.0350 \pm 0.0090)$. We also used relative rate tests only on Neotropical cichlids, to compare evolutionary rates among geophagines, cichlasomines, and heroines, using the other genera as outgroup. We detected significantly higher rates among geophagines $(Z=3.86201, p<0.05)$. If geophagines are excluded from the Neotropical clade, the average rate of substitution among Neotropical (La $=0.0828)$ and African ( $\mathrm{Lb}=0.0603)$ cichlids was not significantly different $(\mathrm{La}-\mathrm{Lb}=0.0225 \pm 0.0133, Z=$ 1.6898). These results suggest that the high evolutionary rates observed among Neotropical cichlids are found mostly among geophagines.

\section{Discussion}

This is the first comprehensive study, based on mtDNA sequence data, to address the phylogenetic relationships among major groups of cichlid fish. Our results show remarkable agreement with previous hypotheses based on morphology and nuclear DNA sequences (Figs. 1-3). 
The phylogenetic utility of the $16 \mathrm{~S}$ mitochondrial gene has been established at several taxonomic levels among vertebrate taxa (e.g., Mindell and Honeycutt 1990; Hillis and Dixon 1991; Mindell and Thacker 1996) and freshwater fish (e.g., Alves-Gomes et al. 1995; Ortí et al. 1996; Murphy and Collier 1997; Ortí and Meyer 1997). In spite of considerable homoplasy, the $16 \mathrm{~S}$ data set contains reliable phylogenetic signal to establish relationships among major lineages of cichlids. The phylogenetic pattern is completely congruent with the fragmentation of Gondwana and suggests drift-vicariance explanations (Stiassny 1991). Cichlids from Madagascar and India are the most basal group to diverge from ancestral African-Neotropical cichlids, which coincides with the drifting of the India-Madagascar subcontinent during the late Jurassic, ca. 150 Ma (Smith et al. 1994). More recently, Neotropical and African cichlids diverged following the opening of the South Atlantic Ocean, close to $65 \mathrm{Ma}$ (Pitman et al. 1993). Similar biogeographic explanations have been proposed for characiform and aplocheiloid fish, based on the same mitochondrial molecular markers (Murphy and Collier 1997; Ortí and Meyer 1997).

The present study, based on a large number of South American genera and representatives of all major African lineages, supports the definition of the Neotropical cichlids as a monophyletic assemblage. Within this group some relevant systematic findings are worth mentioning. (i) In contrast to Oliver (1984), Stiassny (1991), and Kullander (1998) (see Fig. 1), this mitochondrial molecular evidence tentatively placed Heterochromis among African cichlids, as sister group to Hemichromis or as the most basal African cichlid. (ii) In agreement with Kullander (1998), our results placed the geophagine-like South American genus Retroculus as the most basal taxon of the Neotropical cichlid assemblage. (iii) The placement of the genus Cichla has been disputed for several years. Our results clearly show that Cichla belongs to the Neotropical clade, suggesting a close relation with Astronotus, and not with the crenicichlines, as suggested by Stiassny (1991). This result is also supported by cytochrome $b$, ATPase 6,8, and two nuclear genes sequences (Meyer, Farias, and Ortí, unpublished data). (iv) The crenicichlines are nested within the geophagine group. (v) The present results are in agreement with Stiassny (1991) and Kullander (1996), who suggested that the heroines and cichlasomines are monophyletic sister taxa, a viewpoint also supported by our previous analysis (Farias et al. 1998). (vi) Our results place Acaronia with the cichlasomines (Figs. 2 and 3), in contrast with Stiassny's (1991) arrangement, which placed this genus within heroines, and Kullander (1998), who considered Acaronia as the sister group of the cichlasomine-heroine clade. (vii) The Central American species included in the present study (Archocentrus nigrofasciatum, "Cichasoma" citrinellum, and Petenia splendida) are, as expected, closely related to the South American heroines, forming a monophyletic clade with Caquetaia spectabile.

\section{High Rate of Molecular Evolution of South American Cichlids}

Lacustrine African cichlids have recently undergone one of the most rapid adaptive radiations known for vertebrates (Echelle and Kornfield 1984; Greenwood 1984; Meyer et al. 1990; Greenwood 1991; reviewed by Meyer 1993). However, this rapid speciation rate is not correlated with high genetic divergence, since African cichlids are known to exhibit an overall low amount of genetic variation (e.g., Meyer et al. 1990). Recently, Zardoya et al. (1996) found twice as much variation at a nuclear marker (TmoM27) among South American as among African cichlids. Our path length analysis and relative rate tests confirm this finding based on nuclear DNA that, although considerably less speciose than their African counterparts, the Neotropical cichlids are extremely more variable at the molecular level. The rate of nucleotide divergence at the $16 \mathrm{~S}$ mitochondrial fragment in Neotropical cichlids was significantly higher than in the African lineages (Fig. 4). However, the rate acceleration was only significantly higher among geophagines.

In the more than $65 \mathrm{Ma}$ ensuing since the separation of the Gondwanan fragments, Neotropical and African cichlids followed independent evolutionary pathways. Africa and South America have undergone radically different climatic histories since their separation in the Cretaceous. The well-documented paucity of the tropical African flora has been linked to an extensive spread of aridity in that continent following mid-Oligocene global cooling trends (Goldblatt 1993). Biotic factors also may have determined significantly different selective pressures for the two continental ichthyofaunas. For example, notopterids, mormyriforms, knerids, and cypriniforms are freshwater fish groups present in Africa but not in South America. The combination of biotic and abiotic factors may have triggered high extinction rates in Africa, perhaps explaining the currently depauperate characiform fauna in Africa (Lundberg 1993; Ortí and Meyer 1997). Surviving ancestral lineages of African cichlids have recently ( $<1 \mathrm{Ma}$ ) undergone explosive radiations in the East African lakes, accounting for the high number of extant cichlid species and for their low level of genetic differentiation. The predominantly intralacustrine speciation mode in African cichlids might have been shaped mainly by sexual selection and trophic specialization. In contrast, Kullander (1983) suggested that speciation in riverine cichlids in the Neotropics typically occurred by accumulation of genetic changes in allopatric populations living in different river systems but not generally associated with great trophic divergence. Neotropical cichlids might have experienced lower rates of extinction 
and speciation than their African counterparts, preserving primitive characteristics and thereby accumulating higher levels of genetic divergence in some of these lineages.

\section{Appendix: Specimens}

Voucher specimens for most South American samples were deposited in museum collections. Species are listed according to South American suprageneric groups (see Kullander's cichlid web page). The collection numbers are preceded by INPA for the specimens deposited at the Instituto Nacional de Pesquisas da Amazônia, Manaus, Amazonas, Brazil; MPEG for the specimens deposited at the Museu Paraense Emilio Goeldi, Belém, Pará, Brazil; MCP for the specimens deposited at the Museu de Coleção de Peixes de Porto Alegre, Rio Grande do Sul, Brazil; and ZUEC for the specimens deposited at the Museu de História Natural da Universidade Estadual de Campinas, São Paulo, Brazil.

Chaetobranquines: Astronotus ocellatus (INPA 12063), Chaetobranchus flavescens (INPA 9442), Chaetobranchus semifasciatus (INPA 7592).

Cichlasomines: Acaronia nassa (INPA 9747), Aequidens sp. (INPA 3453), Bujurquina sp. (INPA 13438), Cichlasoma amazonarum (INPA 13437), Laetacara curviceps (MPEG 3576).

Crenicichlines: Crenicichla sp. (MPEG 3574), Crenicichla regani (MPEG 3575), Teleocichla centrarchus (INPA 4173).

Heroines: Heros sp. (INPA 9928), Hoplarchus psittacus (INPA 9901), Mesonauta insignis (INPA 13437), Pterophyllum scalare (INPA 13434), Symphysodon aequifasciatus (INPA 13433), Uaru amphiacanthoides (INPA 12061).

Geophagines: Acarichthys heckelli (INPA 363), Biotodoma wavrini (INPA 13435), Geophagus altifrons (INPA 12062), “Geophagus” brasiliensis (ZUEC 3604), Geophagus cf. proximus (INPA 1392), Guianacara sp. (INPA 7742), Gymnogeophagus gymnogenys (MCP 20028), Gymnogeophagus labiatus (MCP 20029), Retroculus sp. (INPA 3428), Retroculus xinguensis (INPA 4282), Satanoperca acuticeps (INPA 11037), Satanoperca jurupari (INPA 9930).

Cichla spp.: Cichla monoculus (INPA 9908), Cichla orinocensis (INPA 9939), Cichla temensis (INPA 9905).

Acknowledgments. We thank the many colleagues who provided tissue samples and species identification: J. Alves-Gomes, E. Feldberg, E. Ferreira, M. Garcia, J. Porto, R. Reis, C. Silva, E. Silva, and J. Zuanon. We are also grateful to S. Kullander for comments on early versions of the manuscript. This work was supported in part by CAPES, Universidade Federal do Pará, Universidade do Amazonas, and University of Nebraska-Lincoln. I.P.F. is a Ph.D. fellow from CAPES. We also acknowledge support through the National Science Foundation (Grants BSR-912367, BSR-9119867, DEB-9615178), the Max-Planck-Society, and the University of Konstanz to A.M.

\section{References}

Alves-Gomes JA, Ortí G, Haygood M, Heiligenberg W, Meyer A (1995) Phylogenetic analysis of the South American electric fishes (order Gymnotiformes) and the evolution of their electrogenic system: a synthesis based on morphology, electrophysiology, and mitochondrial sequence data. Mol Biol Evol 12:298-318

Cichocki FP (1976) Cladistic history of cichlid fishes and reproductive strategies of the American genera Acarichthys, Biotodoma and Geophagus, PhD thesis, University of Michigan, Ann Arbor

Echelle AA, Kornfield I (1984) Evolution of fish species flocks. University of Maine Press, Orono

Farias IP, Schneider H, Sampaio I (1998) Molecular phylogeny of Neotropical cichlids: The relationships of cichlasomines and heroines. In: Malabarba LR, Reis RE, Vari RP, Lucena ZM, Lucena CAS (ed) Phylogeny and classification of Neotropical fishes, Porto Alegre, Edipucrs, pp 499-508

Felsenstein J (1978) Cases of which parsimony and compatibility methods will be positively misleading. Syst Zool 27:401-410

Futuyma DJ (1997) Evolutionary biology, 3rd ed. Sinauer, Sunderland, MA

Greenwood PH (1984) African cichlids and evolutionary theories. In: Echelle AA, Kornfield I (ed) Evolution of fish species flocks. University of Maine Press, Orono, pp 141-154

Greenwood PH (1991) Speciation. In: Keenleyside MHA (ed) Cichlid fishes: Behaviour, ecology and evolution. Chapman and Hall, London, p 378

Goldblatt P (1993) Biological relationships between Africa and South America: An overview. In: Goldblatt P (ed) Biological relationships between Africa and South America. New Haven, CT, Yale University Press, pp 3-14

Hasegawa M, Kishino H, Yano T (1985) Dating of the human-ape splitting by a molecular clock of mitochondrial DNA. J Mol Evol 22:160-174

Hillis DM (1998) Taxonomic sampling, phylogenetic accuracy, and investigator bias. Syst Biol 74:3-8

Hillis DM, Dixon MT (1991) Ribosomal DNA: Molecular evolution and phylogenetic inference. Q Rev Biol 66:411-453

Kaufman L, Liem KF (1982) Fishes of the suborder Labroidei (Pisces: Perciformes): Phylogeny, ecology and evolutionary significance. Breviora Mus Comp Zool 472:1-19

Kidd KK, Sgaramella-Zonta LA (1971) Phylogenetic analysis: concepts and methods. Am J Hum Genet 23:235-252

Kishino H, Hasegawa M (1989) Evaluation of the maximum likelihood estimate of the evolutionary tree topologies from DNA sequence data, and the branching order in Hominoidea. J Mol Evol 29:170179

Kocher TD, Conroy JA, McKaye KR, Stauffer JR, Lockwood SF (1995) Evolution of the ND2 gene in East African cichlids. Mol Phyl Evol 4:420-432

Kullander SO (1983) Review of the South American cichlids, PhD thesis. University of Stockholm, Stockholm, pp 297-440

Kullander SO (1986) Cichlid fishes of the Amazon River drainage of Peru. Swedish Museum of Natural History Stockholm, p 431

Kullander SO (1988) Teleocichla, a new genus of South American rheophilic cichlid fishes with six new species (Teleostei: Cichlid). Copeia 1988:196-230

Kullander SO (1996) Heroina isonycterina, a new genus and species of cichlid fish from western Amazonia, with comments on cichlasomine systematics. Ichthyol Explor Freshwaters 7:149-172

Kullander SO (1998) A phylogeny and classification of the South American Cichlidae (Teleostei: Perciformes). In: Malabarba LR, Reis RE, Vari RP, Lucena ZM, Lucena CAS (eds) Phylogeny and classification of Neotropical fishes, Porto Alegre, Edipucrs, pp 461-498

Kumar S (1996) PHYLTEST: Phylogeny hypothesis testing software. The Pennsylvania State University, University Park 
Lundberg JG (1993) African-South American fresh-water fish clades and continental drift: Problems with a paradigm. In: Goldblatt P (ed) Biological relationships between Africa and South America. Yale University Press, New Haven, CT, pp 156-199

Martin AP, Bermingham E (1998) Systematics and evolution of lower Central American cichlids inferred from analysis of cytochrome $b$ gene sequence. Mol Phyl Evol 9:192-203

Meyer A (1993) Phylogenetic relationships and evolutionary processes in East African cichlid fishes. Trend Ecol Evol 8:279-284

Meyer A (1994) DNA technology and phylogeny of fish: Molecular phylogenetic studies of fish. In: Beaumont AR (ed) Genetic and evolution of aquatic organisms. Chapman and Hall, London

Meyer A, Kocher TD, Basasibwaki P, Wilson AC (1990) Monophyletic origin of Lake Victoria cichlid fishes suggested by mitochondrial DNA sequences. Nature Lond 347:550-553

Mindell DP, Honeycutt RL (1990) Ribosomal RNA in vertebrates: Evolution and phylogenetic applications. Annu Rev Ecol Syst 21: 541-566

Mindell DP, Thacker CE (1996) Rates of molecular evolution: Phylogenetic issues and applications. Annu Rev Ecol Syst 27:279-303

Moran P, Kornfield I (1993) Retention of an ancestral polymorphism in the mbuna species flock (Pisces: Cichlidae) of Lake Malawi. Mol Biol Evol 10:1015-1029

Murphy WJ, Collier GE (1997) A molecular phylogeny for Aplocheiloid fishes (Atherinomorpha, Cyprinodontiformes): The role of vicariance and the origins of annualism. Mol Biol Evol 14(8):790799

Oliver MK (1984) Systematics of African cichlid fishes: Determination of the most primitive taxon, and studies on the haplochromines of Lake Malawi (Teleostei: Cichlidae), PhD thesis. Yale University, New Haven, CT

Ortí G, Meyer A (1997) The radiation of characiform fishes and the limits of resolution of mitochondrial ribosomal DNA sequences. Syst Biol 46(1):75-100

Ortí G, Petry P, Porto JIR, Jegu M, Meyer A (1996) Patterns of nucleotide change in mitochondrial ribosomal RNA genes and the phylogeny of piranhas. J Mol Evol 42:169-182

Palumbi S, Martin A, Romano S, McMillian WO, Stice L, Grabowski G (1991) The simple fool's guide to PCR. University of Hawaii, Honolulu

Pitman WCI, Cande S, LaBrecque J, Pindell J (1993) Fragmentation of Gondwana: The separation of Africa from South America. In: Goldblatt P (ed) Biological relationships between African and South America. Yale University Press, New Haven, CT

Regan CT (1906) A revision of the fishes of the South-American cichlid genera of Cichla, Chaetobranchus, and Chaetobranchopsis, with notes on the genera of American Cichlidae. Ann Mag Nat Hist 7(17):230-239

Roe KL, Conkel D, Lydeard C (1997) Molecular systematic of Middle
American cichlid fishes and evolution of trophic-types in Cichlasoma (Amphilophus) and C. (Thorichthys). Mol Phyl Evol 7:366376

Sambrook J, Fritsch EF, Maniatis T (1989) Molecular cloning: A laboratory manual, 2nd ed. Cold Spring Harbor Laboratory Press, Cold Spring Harbor, NY

Smith AG, Smith DG, Funnel BM (1994) Atlas of Mesozoic and Cenozoic Coastlines. Cambridge University Press, Cambridge

Stiassny MLJ (1987) Cichlid familial intrarelationships and the placement of the Neotropical genus Cichla (Perciformes, Labroidei). J Nat Hist 21:1311-1331

Stiassny MLJ (1991) Phylogenetic intrarelationships of the family Cichlidae: An overview. In: Keenleyside MHA (ed) Cichlid fishes. Behaviour, ecology and evolution. Chapman and Hall, London, p 378

Storey M, Mahoney JJ, Saunders AD, Duncan RA, Kelley SP, Coffin MF (1995) Timing of hot spot-related volcanism and breakup of Madagascar and India. Science 267:852-855

Streelman JT, Karl SA (1997) Reconstructing labroid evolution with single-copy nuclear DNA. Proc R Soc Lond B 264:1011-1020

Streelman JT, Zardoya R, Meyer A, Karl SA (1998) Multi-locus phylogeny of cichlid fishes (Pisces: Perciformes): Evolutionary comparison of microsatellite and single-copy nuclear loci. Mol Biol Evol 15:798-808

Sturmbauer C, Meyer A (1992) Genetic divergence, speciation and morphological stasis in a lineage of African cichlid fishes. Nature Lond 359:578-581

Sültmann H, Mayer WE, Figueroa F, Tichy H, Klein J (1995) Phylogenetic analysis of cichlid fishes using nuclear DNA markers. Mol Biol Evol 12:1033-1047

Swofford DL (1998) PAUP*. Phylogenetic analysis using parsimony and other methods, Version 4.0d61. Sinauer, Sunderland, MA (in press)

Takezaki N, Rzhetsky A, Nei M (1995) Phylogenetic test of the molecular clock and linearized trees. Mol Biol Evol 12:823-833

Templeton AR (1983) Phylogenetic inference from restriction endonuclease cleavage site maps with particular reference to the humans and apes. Evolution 37:221-244

Thompson JD, Higgins DG, Gibson TJ (1994) CLUSTAL W: Improving the sensitivity of progressive multiple sequence alignment through sequence weighting, position specific gap penalties and weight matrix choice. Nucleic Acids Res 22:4673-4680

Yang Z (1993) Maximum likelihood estimation of phylogeny from DNA sequences when substitution rates differ over sites. Mol Biol Evol 10:1396-1401

Zardoya R, Vollmer DM, Craddock C, Streelman JT, Karl SA, Meyer A (1996) Evolutionary conservation of microsatellite flanking regions and their use in resolving the phylogeny of cichlid fishes (Pisces: Perciformes). Proc R Soc Lond B 263:1589-1598 